5. Schwellnus MP, Derman EW, Noakes TD. Aetiology of skeletal muscle "cramps" during exercise: a novel hypothesis. J Sports Sci. 1997;15:277-285.

6. Bennett BL, Hew-Butler T, Hoffman MD, Rogers IR, Rosner MH. Wilderness Medical Society practice guidelines for treatment of exercise-associated hyponatremia. Wilderness Environ Med. 2013;24:228-240.

7. Joslin J, Worthing R, Black T, Grant WD, Kotlyar T, Wojcik SM. Analysis of weight change and Borg rating of perceived exertion as measurements of runner health and safety during a 6-day, multistage, remote ultramarathon. Clin J Sports Med. 2013 Nov 26. [Epub ahead of print].

8. Noakes T. International Marathon Medical Directors Association. Fluid replacement during marathon running. Clin J Sports Med. 2003;13:309-318.

\section{Keeping a Broad Perspective: Reply Regarding the Wilderness Medical Society Practice Guidelines for the Prevention and Treatment of Heat-Related Illness}

\section{To the Editor:}

Our recently published WMS Practice Guidelines for the Prevention and Treatment of Heat-Related Illness ${ }^{1}$ were intended to provide assistance to all those who may be affected negatively by the heat, from gardeners in their backyard to laborers at work, passive observers at outdoor events, and the wilderness adventurer or athlete. We would be remiss without mention of the more benign manifestations of diseases that occur, and we strongly disagree that by discussion of these we "detract focus from the one true heat illness: heat stroke." In fact, the opposite is true as the concluding sentence of our introductory paragraph emphatically stated that the focus of the practice group was on the exploration of exertional heat stroke (EHS). And as such, we provide ample data and recommendations that support cold-water immersion as the fastest and safest cooling method for EHS.

Readers of the Practice Guidelines may have misunderstood the concept of "spectrum," and confused it with "continuum." The spectrum discussed denoted the range of injuries that can and often do occur in hot environments. We made no claim that one minor injury leads to another in stepwise progression, as Joslin et al erroneously implied, the one caveat being that a severely hyperthermic heat-stressed individual may progress to heat stroke if left unrecognized and untreated, a selfevident statement that has been unfortunately witnessed by several of the Practice Guideline authors.

Provision of useful and clinically oriented recommendations required us to keep a broad perspective on our potential audience, and we caution our colleagues who might generalize the proposed pathophysiology of exertion-associated muscle cramps, collapse, exhaustion, and weight loss and hyperthermia in well-trained athletes to the population at large. We have previously discussed and clarified these terms in a prior Letter to the Editor of Wilderness \& Environmental Medicine ("The importance of keeping cool"). Please keep in mind that these recommendations are based in the theory that euhydration may prevent progression of hyperthermia or severity of heat illness. ${ }^{2-5}$ As with any syndrome, the use of words such as heat syncope or heat exhaustion does not mean direct cause and effect, but rather a strong contextual association that may have descriptive and epidemiological merit, if not pathophysiologic precision, in broader populations. We agree that heat exhaustion is a nebulous term, as there is little documentation on presenting symptoms, signs, or treatments, and although people may be normothermic, they may also be mildly hyperthermic (see Table 2 in Practice Guidelines). ${ }^{1}$ When evidence was scant or in some cases even lacking, we chose to promote a balanced risk and benefit recommendation from the extrapolated literature at hand. Cooling and isotonic hydration are often comforting and resuscitative in many mild to moderate forms of heat illness in which there is a low risk in the absence of mental status changes - even in the endurance athlete. ${ }^{6,7}$

The point of view by Joslin et al is welcome, but their promoted "lexicon" should not be expanded comprehensively beyond that of the endurance athlete. Furthermore, their definition of "true heat stroke [as] exertional hyperthermia" is misinformed, as exertional hyperthermia is not synonymous with heat stroke. ${ }^{8}$ Any claim to the contrary is unfortunate because it ignores the substantial morbidity and mortality the world over of the passive or "classic" heat stroke victim. Although the authors of the Practice Guidelines are biased toward wilderness-oriented pastimes and practices, our recommendations were meant to be broadly inclusive to potentially optimize the most benefit to the most people.

Grant S. Lipman, MD Stanford, $C A$

Kurt P. Eifling, MD St. Louis, MO

Mark A. Ellis, MD Spartanburg, SC

Flavio G. Gaudio, MD New York, NY 
Edward M. Otten, MD

Cincinnati, $\mathrm{OH}$

Colin K. Grissom, MD

Salt Lake City, UT

\section{References}

1. Lipman GS, Eifling KP, Ellis MA, Gaudio FG, Otten EM, Grissom CK. Wilderness Medical Society Practice Guidelines for the prevention and treatment of heat-related illness. Wilderness Environ Med. 2013;24:351-361.

2. Coris EE, Ramirez AM, Van Durme DJ. Heat illness in athletes: the dangerous combination of heat, humidity and exercise. Sports Med. 2004;34:9-16.
3. Sawka MN, Latzka WA, Matott RP, Montain SJ. Hydration effects on temperature regulation. Int J Sports Med. 1998;19 (Suppl 2):S108-S110.

4. Bouchama A, Knochel JP. Heat stroke. $N$ Engl J Med. 2002;346:1978-1988.

5. Casa DJ, Armstrong LE, Hillman SK, et al. National athletic trainers' association position statement: fluid replacement for athletes. J Athl Train. 2000;35:212-224.

6. Asplund CA, O'Connor FG, Noakes TD. Exerciseassociated collapse: an evidence-based review and primer for clinicians. Br J Sports Med. 2011;45:1157-1162.

7. Khodaee M, Ansari M. Common ultramarathon injuries and illnesses: race day management. Current Sports Med Rep. 2012;11:290-297.

8. Byrne C, Lee JK, Chew SA, Lim CL, Tan EY. Continuous thermoregulatory responses to mass-participation distance running in heat. Med Sci Sports Exerc. 2006;38: 803-810. 